\title{
Longitudinal analysis of the patient pathways to diagnosis of psoriatic arthritis
}

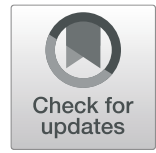

Alexis Ogdie ${ }^{1 *}$ (D), Martin Rozycki ${ }^{2}$, Theresa Arndt ${ }^{2}$, Cheng Shi ${ }^{3}$, Nina Kim ${ }^{4,5}$ and Peter Hur ${ }^{3}$

\begin{abstract}
Background: The occurrence of health events preceding a psoriatic arthritis (PSA) diagnosis may serve as predictors of diagnosis. We sought to assess patients' real-world experiences in obtaining a PsA diagnosis.

Methods: This retrospective cohort study analyzed MarketScan claims data from January 2006 to April 2019. Included were adult patients with $\geq 2$ PsA diagnoses (ICD-9-CM/ICD-10-CM) $\geq 30$ days apart with $\geq 6$ years of continuous enrolment before PsA diagnosis. Controls were matched 2:1 to patients with PsA. Health events (diagnoses and provider types) were analyzed before PSA diagnosis and additionally stratified by presence of psoriasis.

Results: Of 13,661 patients, those with PsA had an increased history of coding for arthritis and dermatologic issues (osteoarthritis [48\% vs $22 \%]$, rheumatoid arthritis [18\% vs $2 \%]$, and psoriasis [61\% vs $2 \%]$ ) vs those without PsA. Diagnoses of arthritis, axial symptoms, and tendonitis/enthesitis increased over time preceding PsA diagnosis; notably, a sharp rise in psoriasis diagnoses was observed 6 months before PsA diagnosis. Rheumatology consults were more common immediately preceding a PsA diagnosis. Dermatologists were unlikely to code for arthritis and musculoskeletal issues, while rheumatologists were unlikely to code for psoriasis; general practitioners focused on axial and musculoskeletal symptoms. PsA was most commonly diagnosed by rheumatologists (40\%), general practitioners (22\%), and dermatologists (7\%).

Conclusions: Rheumatologists, general practitioners, and dermatologists diagnosed two thirds of patients with PsA. Musculoskeletal symptoms were common preceding a PsA diagnosis. Greater awareness of patterns of health events may alert healthcare providers to suspect a diagnosis of PsA.
\end{abstract}

\section{Background}

Psoriatic arthritis (PsA) is a chronic inflammatory disease affecting the skin and musculoskeletal system with various manifestations $[1,2]$. PsA is typically characterized by 6 clinical domains: axial disorders, nail disease, skin disease, peripheral disease, enthesitis, and dactylitis, either alone or in combination [3]. PsA is also associated with many comorbidities [4] that collectively impair patients' quality of life, overall function, and clinical burden [5]. A timely diagnosis of PsA is critical

\footnotetext{
* Correspondence: ogdiea@pennmedicine.upenn.edu

'Perelman School of Medicine at the University of Pennsylvania, Philadelphia, PA, USA

Full list of author information is available at the end of the article
}

because a delay in diagnosis negatively impacts patient outcomes [6,7].

Unfortunately, diagnostic delay is common in PsA. In a cross-sectional study of 203 participants with selfreported PsA in the USA, approximately one third received their diagnosis within 6 months to 4 years, while another one third had to wait for $>5$ years [8]. These participants also consulted with numerous healthcare providers prior to receiving their diagnosis. A 6-month delay from PsA symptom onset to initial rheumatology consult may lead to joint erosion and damage $[9,10]$. An increased awareness of the heterogeneity of PsA symptoms and diagnostic barriers may lead to a timely diagnosis.

Our study aimed to assess patient experiences in the period prior to diagnosis of PsA using administrative 
claims data. We described and analyzed health events (i.e., diagnosis codes and provider types consulted by patients) prior to PsA diagnosis to better understand a patient's journey to diagnosis.

\section{Materials and methods \\ Data source}

This retrospective cohort study used administrative claims data from patients in the Truven MarketScan research databases [11] from January 2006 to April 2019. Comprising 3 core claims databases (Commercial, Medicare Supplemental, and Medicaid), the MarketScan records represent one of the largest collections of deidentified US patient data available for healthcare research, with $>263$ million covered lives in 2020. Data sets include the inpatient, outpatient, and outpatient prescription drug experience of several million employees and their dependents (annually), covered under a variety of fee-for-service and capitated health plans, including exclusive provider organizations, preferred provider organizations, point-of-service plans, indemnity plans, and health maintenance organizations. These databases provide detailed cost, utilization, and outcomes data for healthcare services performed in both inpatient and outpatient settings. The medical claims are linked to outpatient prescription drug claims and person-level enrolment data using unique enrollee identifiers.

\section{Data variables and study population}

Variables considered in this study included health events and demographics extracted entirely from the claims database; no prefiltering of any variable category was performed. To be included in our study, patients with PsA must have received 2 diagnoses of PsA, specified by the International Classification of Diseases, Ninth and Tenth Revisions, Clinical Modification (ICD-9-CM and ICD-10-CM), $\geq 30$ days apart to account for potential clustering of care immediately following the first diagnosis of PsA and increase the confidence that the diagnosis is correct [12-14]; patients were aged $\geq 18$ years at diagnosis and had $\geq 6$ years of continuous enrolment prior to PsA diagnosis. The following diagnosis codes were included: 696.0 (psoriatic arthropathy), L40.50 (arthropathic psoriasis, unspecified), L40.51 (distal interphalangeal psoriatic arthropathy), L40.52 (psoriatic arthritis mutilans), L40.53 (psoriatic spondylitis), L40.54 (psoriatic juvenile arthropathy), and L40.59 (other psoriatic arthropathy). Controls (those without a diagnosis of PsA) were matched 2:1 to patients with PsA for age, sex, insurance, and enrolment duration (i.e., non-PsA controls were enrolled in the database for the same length of time as their associated PsA patient so that the index date for controls was the end of the matched $\geq 6$-year period that terminated in "no PsA").
The data analyzed in this study included the demographic variables mentioned above as well as data on health events. A health event was defined as any health service provided to a patient in the preindex period, derived from their medical and pharmacy claims history. Health events included PsA diagnosis codes (ICD-9-CM and ICD-10-CM) and specialty physician types (e.g., general practitioners, dermatologists, rheumatologists) as enumerated by the MarketScan databases. Information on health events was captured every 6 months for the 6 years prior to PsA diagnosis. Results were also stratified by the presence of psoriasis vs no psoriasis prior to PsA diagnosis.

This study was conducted in accordance with the Guidelines for Good Pharmacoepidemiology Practices of the International Society for Pharmacoepidemiology, the Strengthening the Reporting of Observational Studies in Epidemiology guidelines, and the ethical principles in the Declaration of Helsinki. All database records were fully compliant with US patient confidentiality requirements, including the Health Insurance Portability and Accountability Act of 1996. As this study is a retrospective analysis of deidentified claims data in compliance with US patient confidentiality requirements and did not involve the collection, use, or transmittal of individually identifiable data, institutional review board approval was not required to conduct this study.

\section{Results}

\section{Patient demographics and diagnosis history}

Of $>265$ million patients in the MarketScan databases, 280,311 patients had $\geq 1$ diagnosis of PsA and 174,524 patients had $\geq 2$ diagnoses of PsA 30 days apart, of whom 172,119 patients were aged $\geq 18$ years at the index date. Of these, a final cohort of 13,661 patients had $\geq 6$ years of continuous enrolment in the database, fulfilling the criteria for inclusion in the study. The mean age was 55.8 years and $60.2 \%$ were women; baseline demographics of patients diagnosed with PsA and nonPsA controls are shown in Table 1.

Compared with controls, patients with PsA received more codes for arthritis and skin issues, including osteoarthritis (OA; $47.8 \%$ vs $21.7 \%)$, rheumatoid arthritis $(18.1 \%$ vs $2.3 \%$ ), inflammatory polyarthropathy (IA; $17.6 \%$ vs $1.0 \%$ ), and psoriasis (61.3\% vs $1.9 \%$ ) (Fig. 1). Patients with PsA without a prior diagnosis of psoriasis received more codes for other forms of arthritis compared with those with PsA and psoriasis, including OA (52.5\% vs $44.8 \%$ ), rheumatoid arthritis (26.8\% vs $12.6 \%$ ), and IA ( $25.6 \%$ vs 12.5\%) (Fig. 2).

Patients received a variety of diagnosis codes for their condition prior to the first PsA diagnosis code, suggestive of misdiagnosis. These patients received many symptom codes over the 6-year period prior to 
Table 1 Baseline demographics of patients diagnosed with PSA and non-PsA controls

\begin{tabular}{lll}
\hline Characteristic & Patients with PsA $(\mathbf{N}=\mathbf{1 3}, \mathbf{6 6 1})$ & Non-PsA controls $\mathbf{~}^{\mathbf{a}}(\mathbf{N}=\mathbf{2 6 , 7 2 9})$ \\
\hline Age, mean (SD), years & $55.8(12.6)$ & $55.9(12.7)$ \\
Female, \% & 60.2 & 60.4 \\
Insurance type, \% & 78.6 & 78.6 \\
$\quad$ Commercial & 15.1 & 15.3 \\
Medicaid & 6.3 & 6.1 \\
$\quad$ Medicare & & 30.0 \\
US geographical region, \% & 21.7 & 48.7 \\
$\quad$ Midwest & 15.2 & 11.9 \\
$\quad$ Northeast & 43.6 & 3.2 \\
South & 12.9 & 6.2 \\
West & 6.6 & 3 \\
Unknown &
\end{tabular}

PSA Psoriatic arthritis

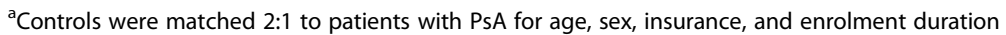

PsA diagnosis (Fig. 3). More than 10\% of patients had coding for axial manifestations, nonspecific musculoskeletal manifestations, psoriasis, and/or skin manifestations 6 years prior to receiving their PsA diagnosis; by the time patients were diagnosed with PsA, > 20\% of patients had diagnoses of nonspecific musculoskeletal manifestations, skin manifestations, axial manifestations, psoriasis, OA, and/or tendonitis/enthesitis. In the final 6-month period prior to
PsA diagnosis, a sharp rise in the cumulative number of psoriasis diagnoses was observed (48.0 to $60.5 \%$ ); larger increases in the number of diagnoses of $\mathrm{OA}$ (40.4 to $48.0 \%)$ and IA (10.8 to $17.6 \%)$ were also noted in the same timeframe.

\section{Physician specialty analysis}

General practitioners, rheumatologists, and dermatologists were seen with increasing frequency approaching

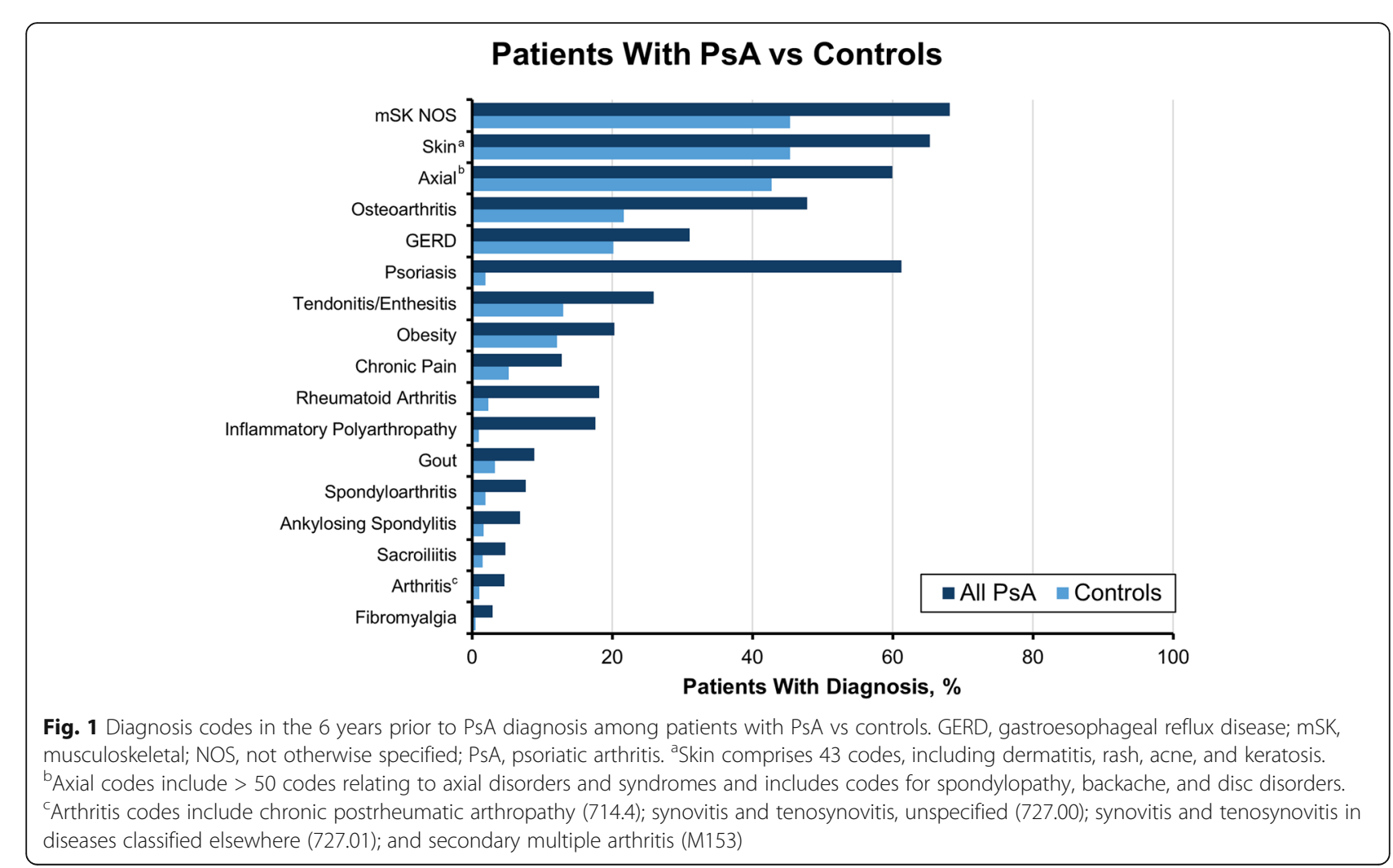




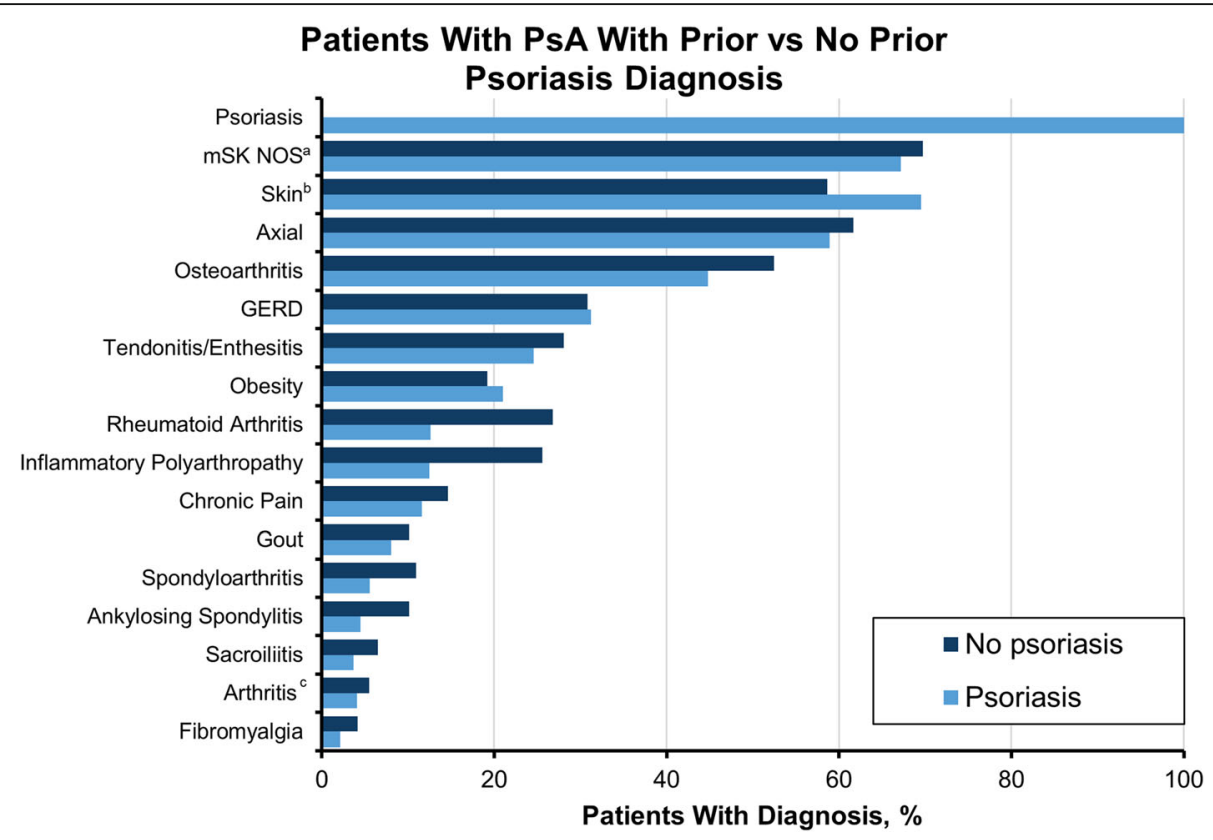

Fig. 2 Diagnosis codes in the 6 years prior to PSA diagnosis among patients with PsA with prior vs no prior psoriasis diagnosis. GERD, gastroesophageal reflux disease; mSK, musculoskeletal; NOS, not otherwise specified; PsA, psoriatic arthritis. ${ }^{a}$ Skin comprises 43 codes, including dermatitis, rash, acne, and keratosis. ${ }^{b}$ Axial codes include $>50$ codes relating to axial disorders and syndromes and includes codes for spondylopathy, backache, and disc disorders. 'Arthritis codes include chronic postrheumatic arthropathy (714.4); synovitis and tenosynovitis, unspecified (727.00); synovitis and tenosynovitis in diseases classified elsewhere (727.01); and secondary multiple arthritis (M153)

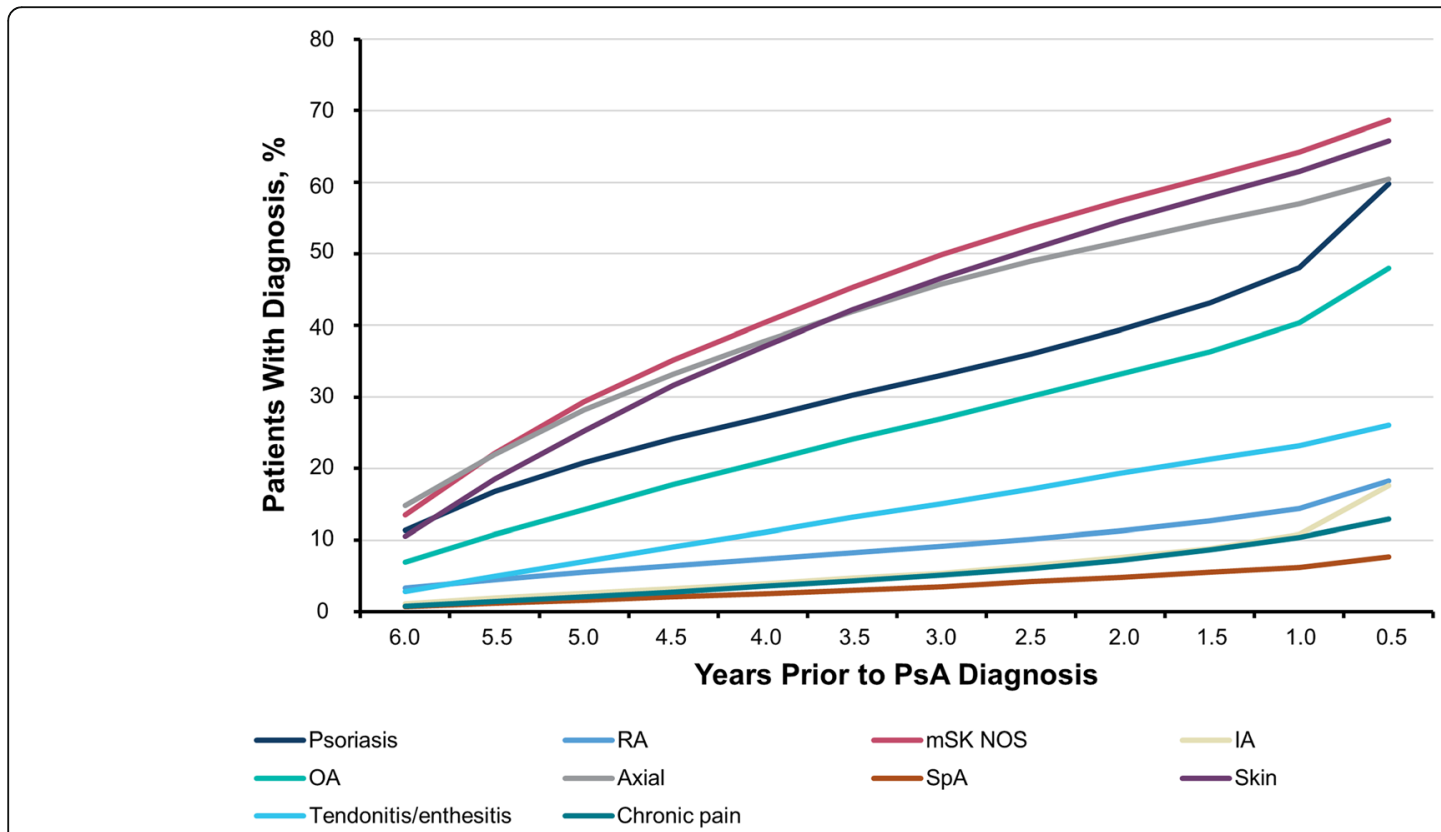

Fig. 3 Cumulative patient journey through different diagnoses in the 6 years prior to PSA diagnosis. IA, inflammatory polyarthropathy; mSK, musculoskeletal; NOS, not otherwise specified; OA, osteoarthritis; PSA, psoriatic arthritis; RA, rheumatoid arthritis; SpA, spondyloarthritis 
diagnosis (Fig. 4). A large proportion of patients received medical care from general practitioners in the 6 years preceding the PsA diagnosis, with the cumulative proportion of patients increasing from $50.0 \%$ at 6 years prior to PsA diagnosis to $88.1 \%$ at 6 months prior to diagnosis. In this 6-year window, patients were symptomatic and received various non-PsA diagnosis codes for their condition, as shown in Fig. 3. A sizable and abrupt increase in the number of rheumatology visits was observed in the final 6-month period immediately before the diagnosis of PsA (22.9 to 34.9\%). Large increases were also observed for dermatologist (54.4 to $59.0 \%$ ) and orthopedic surgeon (44.1 to $48.2 \%$ ) visits over the same time period.

Diagnoses made prior to the diagnosis of PsA differed by the type of provider that patients saw (Fig. 5). Dermatologists were less likely than other providers to enter codes for arthritis and musculoskeletal issues (< $1 \%$ ), while rheumatologists were unlikely to code for psoriasis (15.5\%) but had a fairly even distribution across different types of arthritis (IA, 17.4\%; OA, 17.2\%; and RA, 13.4\%). General practitioners focused more on axial symptoms (18.5\%) and nonspecific musculoskeletal manifestations (18.0\%) than arthritis diagnoses. PsA was most commonly diagnosed by rheumatologists (39.8\%) but was diagnosed in $22.3 \%$ and $7.3 \%$ of cases by general practitioners and dermatologists, respectively (Fig. 6).

\section{Discussion}

In this study, we analyzed occurrences of health events (i.e., diagnosis codes and types of healthcare provider seen by patients) using the MarketScan research databases prior to the diagnosis of PsA to better comprehend a patient's journey in obtaining a PsA diagnosis. Overall, nonspecific musculoskeletal manifestations and non-PsA diagnoses were common up to 6 years before the diagnosis of PsA compared with controls without PsA. The diagnoses and codes entered prior to PsA diagnosis varied by provider type. Rheumatologists and dermatologists, unsurprisingly, were more likely to code for different types of arthritis and skin manifestations/psoriasis, respectively. Rheumatologists accounted for $40 \%$ of the PsA diagnoses, whereas general practitioners and dermatologists combined to make $30 \%$ of PsA diagnoses, and the remaining $30 \%$ of diagnoses were made by physicians in other specialties.

Compared with controls, patients with PsA in our study received a variety of additional non-PsA diagnosis codes, suggestive of PsA symptom build-up, in the 6 years preceding diagnosis. An analysis of administrative data in Canada similarly reported a build-up of musculoskeletal symptoms as early as 5 years prior to the diagnosis of PsA [15]. Patients manifesting these symptoms have well-documented difficulties ("unable to do" or "with much difficulty") with various daily tasks, including the inability to bend down to pick up items from the floor or to walk on flat ground [16]. These, in combination with other negative psychological, social, and economic impacts, contribute significantly to the overall burden of disease and poor quality of life [17-20].

Timely referral of a patient with potential PsA for rheumatology evaluation is critical to improving

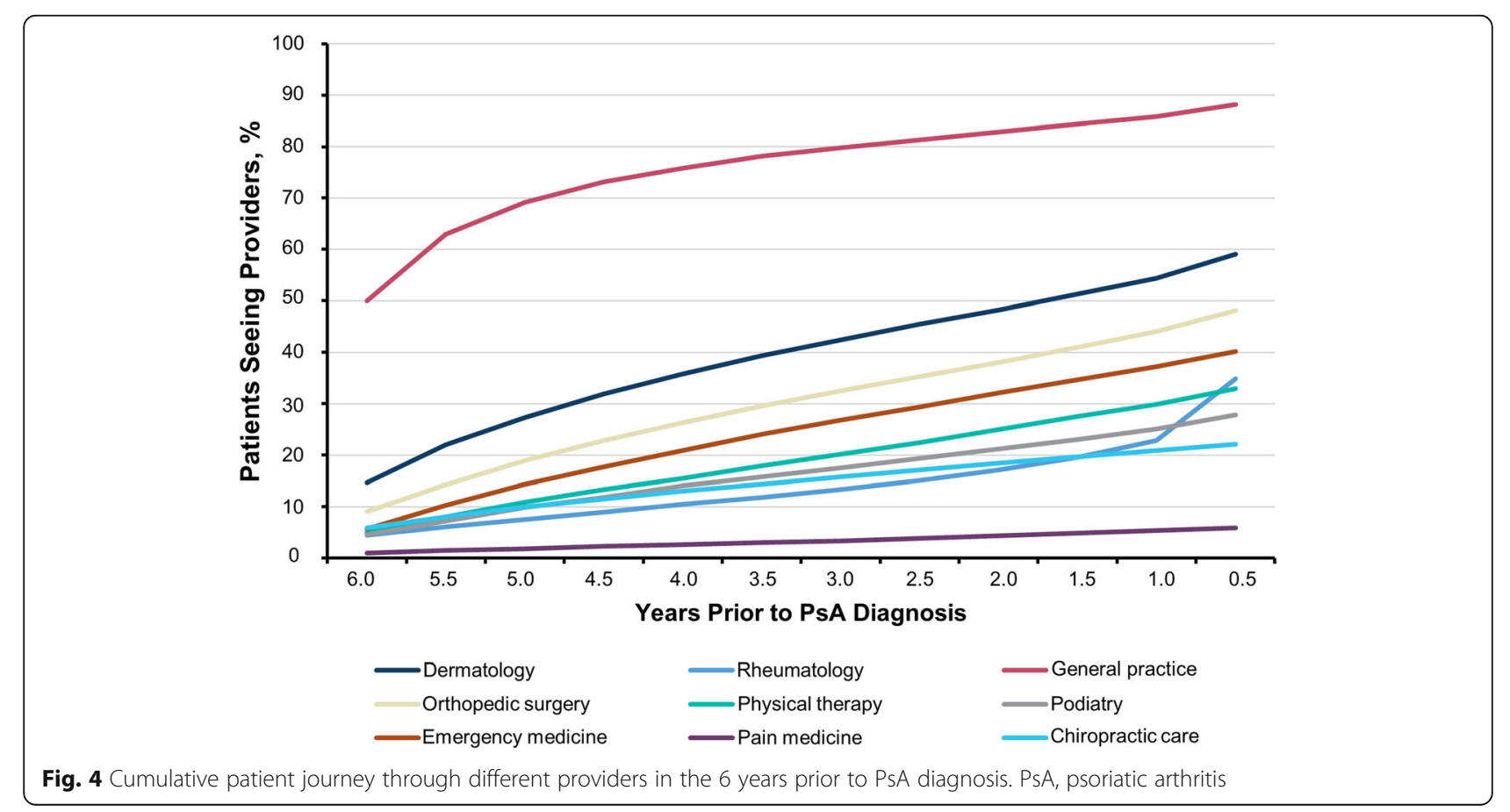




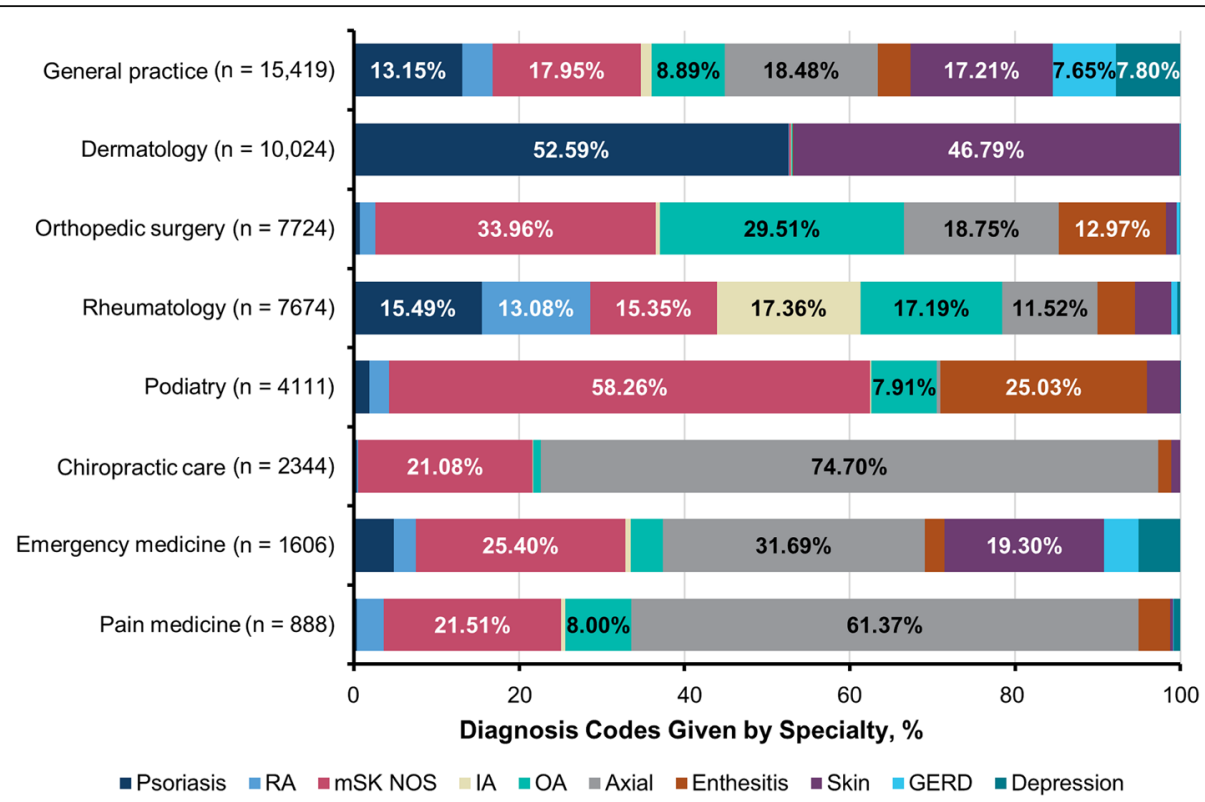

Fig. 5 Coding patterns by specialty — fractions by specialty in the 6 years prior to PsA diagnosis. GERD, gastroesophageal reflux disease; IA, inflammatory polyarthropathy; mSK, musculoskeletal; NOS, not otherwise specified; OA, osteoarthritis; PsA, psoriatic arthritis; RA, rheumatoid arthritis

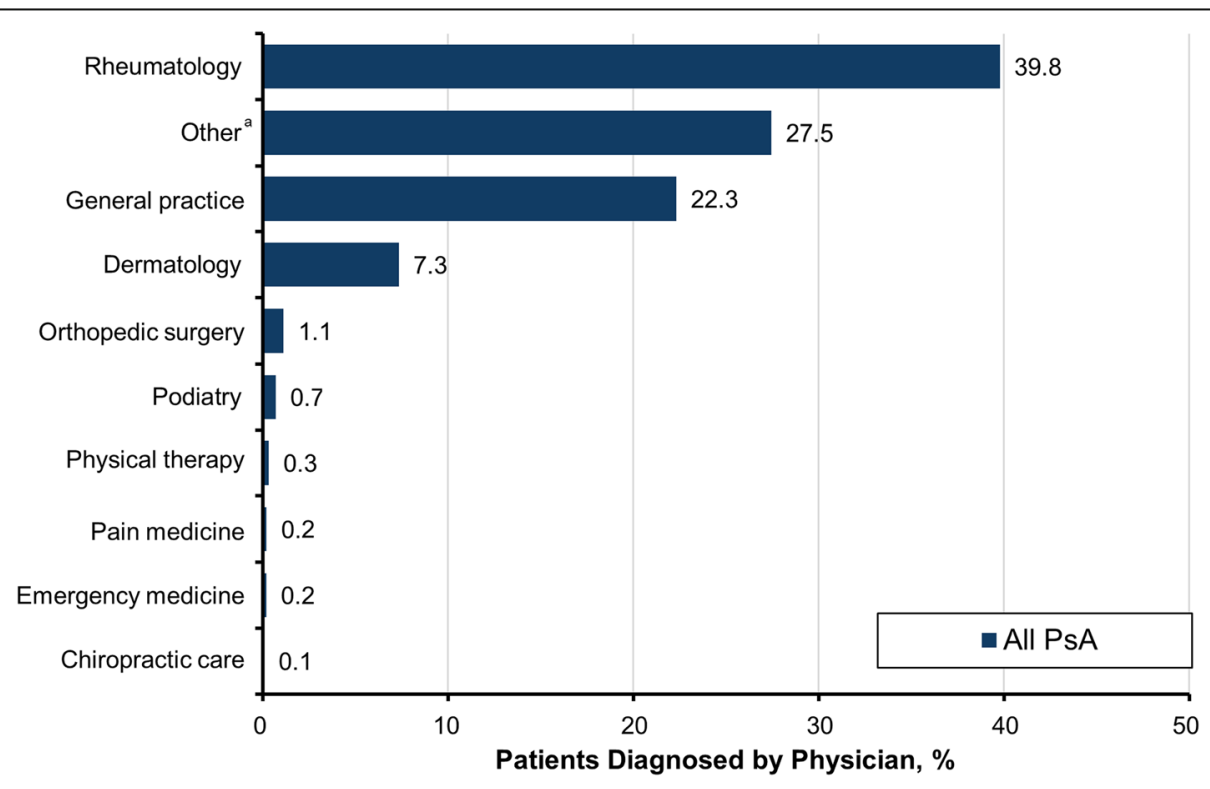

Fig. 6 Distribution of physicians who diagnosed patients with PSA. PsA, psoriatic arthritis. ${ }^{a}$ Other comprises 71 provider types from other disciplines, including pathology, radiology, endocrinology, and ophthalmology based on provider codes, with most provider types contributing a very small percentage of the patients diagnosed. The top 4 provider types in the "other" category were "laboratory" (11.0\%), "medical doctor/MD" (4.9\%), "multispecialty physician group" (3.9\%), and "other facility" (3.0\%). These contribute to the "other" group without providing specific information on the type of provider making the diagnosis and thus were grouped as "other" to focus on those physicians who routinely encounter patients with PSA 
outcomes for patients with PsA, and this has been recognized for some time $[9,21,22]$. The ability to identify PsA symptoms early in the disease course, in addition to recognizing specific trends and patterns in a patient's pursuit for diagnosis, may permit prompt referral to appropriate specialists, leading to an earlier diagnosis of PsA. These health events may serve as potential predictors of a PsA diagnosis with regard to the many diagnoses received and healthcare providers seen. Identifying the subset of the patient population for screening and referral may be additionally useful to avoid overwhelming rheumatology healthcare providers with high volumes of patients with musculoskeletal symptoms.

Another notable finding in this study was an abrupt increase in the number of psoriasis diagnoses observed preceding the diagnosis of PsA. Although more than two thirds of patients with PsA develop dermatologic lesions prior to joint and musculoskeletal manifestations, the symptoms are not often recognized as related to each other $[16,23,24]$. A prior study reported that almost $70 \%$ of patients sought medical help from 1 to 2 healthcare providers and $25 \%$ saw $\geq 3$ providers within 2 years prior to the survey before receiving a diagnosis of psoriasis [25]. Furthermore, we know that inflammation in the joints and entheses of patients with psoriasis often begins with a subclinical phase without clear physical examination findings [26, 27]. Dermatologists are in a prime position to detect PsA early and rapidly refer patients to rheumatology, but we know there is a gap $[28,29]$. In fact, in this study, we saw that dermatologists rarely coded for musculoskeletal findings, potentially suggesting that they are not asking about them or that patients are not reporting musculoskeletal symptoms to their dermatologist. Yet, undiagnosed PsA is commonly observed in dermatology offices [30, 31] and has been recognized in almost one third of patients with psoriasis [29, 31-34]. Patients with psoriasis presenting with PsA manifestations, comprising arthritis, enthesitis, dactylitis, nail disease, and spondylitis, should be evaluated for PsA [35].

Collectively, our study may indicate an opportunity for earlier detection of PsA as characterized by nonspecific musculoskeletal manifestations and skin symptoms and suggests that these musculoskeletal manifestations may be undercoded or underrecognized in clinical practice [36]; improved outcomes have been observed among patients who were promptly treated after receiving a diagnosis of PsA [21, 22, 37]. Approaching PsA diagnosis, general practice, rheumatology, and dermatology visits were much more frequent, suggesting the need for patient education in recognizing symptoms of arthritic conditions. A delay in diagnosis due to initial medical consults with general practitioners and other nonrheumatology healthcare providers is well recognized $[8,16$,
18]. An integrated, multidisciplinary method is critical for comprehensive medical care for patients with PsA. Rheumatologists and dermatologists are in an ideal position to mediate collaborations with other healthcare providers and patient advocacy and support groups for the design of a patient-centric intervention and treatment strategy [38, 39]. An improvement in skin and joint symptoms was observed in more than half of patients with psoriasis and PsA after treatment modifications facilitated by rheumatologists and dermatologists $[38,40]$. However, as the number of rheumatologists is predicted to decline by $30 \%$ by the year 2030 [41], more innovative approaches to patient care are needed. Integrating the use of technology, such as software that calculates composite targets based on both physicianand patient-reported outcomes, to determine disease activity status may be implemented [3]. Validated screening instruments may also be used [42-44], along with patient education and referral guidelines for general practitioners [39, 45]. The future development of applications that tabulate risk or likelihood of disease based on patient data may be a useful undertaking. In creating algorithms using electronic medical records or administrative (i.e., insurance) databases to identify patients who may have early PsA, data scientists need to consider that the diagnosis pathways may differ from patient to patient, depending on the sequence of provider specialties consulted by the patient.

A more patient-centric disease management method may be implemented with the use of currently available diagnostic tools, such as electronic applications allowing the upload of patient-reported outcomes prior to doctor visits [3]. This may help increase patient awareness of symptoms, enhance self-management, improve patientprovider communication, and help predict which patients may be "at risk" or have a high likelihood of actually having PsA. For example, the healthcare provider would enter notes and codes from the visit into the same software, and if an insurer were to use these data, they could send a communication or a pop-up notification to the physician caring for the patient to consider PsA as a potential diagnosis based on the set of codes entered.

There are limitations with our study that should be considered when interpreting the findings. As with any analysis of claims-based data, miscoding by healthcare providers may have occurred; however, the inclusion of patients with PsA who had received 2 diagnosis codes, instead of only 1 diagnosis code, may decrease the likelihood of miscoding or misdiagnosis. Additionally, some healthcare services may not be included in claims databases, leading to the underestimation of overall disease and economic burden. ICD-9-CM and ICD-10-CM codes are used for billing and may not reflect an accurate diagnosis, and there was no independent 
confirmation of patient diagnoses. Lastly, because this is an analysis of US claims data, these findings may not be fully representative of other countries with different healthcare systems. This analysis is informative, regardless, by evaluating the real-world diagnostic experience of a large number of patients.

\section{Conclusions}

In summary, this study aimed to increase understanding of the patient journey to a diagnosis of PsA and underscores the need for prompt and improved diagnostic approaches from a health systems perspective. An overall prevalence of skin and nonspecific musculoskeletal manifestations, in addition to consultations with various types of healthcare providers, may collectively serve as predictors of PsA. Greater awareness of patterns or trends of health events as seen in our study may alert general practitioners and other healthcare providers in primary care settings to suspect a diagnosis of PsA among their patients. From a research standpoint, patients displaying these predictors may be followed to monitor for PsA development; future analyses will examine sequence of health events as predictors of PsA diagnosis. Using such algorithms may also help raise a differential diagnosis that the physician may not have thought of otherwise. As PsA is associated with considerable healthcare costs [46], the number of non-PsA diagnoses, potentially suggestive of misdiagnoses, and healthcare visits across different types of providers suggest the increased utilization of healthcare resources. The clinical and economic burden associated with PsA will most likely impact disease management and medical and pharmacy policy formulation. Increased awareness and understanding of diagnostic barriers may lead to timelier diagnosis, cost savings, and appropriate intervention to improve outcomes.

\section{Abbreviations}

IA: Inflammatory polyarthropathy; ICD-9-CM and ICD-10-CM: International Classification of Diseases, Ninth and Tenth Revision, Clinical Modification; OA: Osteoarthritis; PsA: Psoriatic arthritis

\section{Acknowledgements \\ Support for third-party writing assistance for this manuscript, furnished by Kheng Bekdache, PhD, and Eric Deutsch, PhD, CMPP, of Health Interactions, Inc., was provided by Novartis Pharmaceuticals Corporation, East Hanover, NJ.}

\section{Authors' contributions}

All authors contributed to the study design, data analysis, and manuscript preparation. The author(s) read and approved the final manuscript.

\section{Authors' information}

Martin Rozycki and Theresa Arndt were Employee of HVH Precision Analytics, LLC, Wayne, PA, USA, at the time of the analysis. Nina Kim was Postdoctoral fellow at the University of Texas at Austin and Baylor Scott and White Health, providing services to Novartis Pharmaceuticals Corporation, at the time of the analysis.

\section{Funding}

This study was funded by Novartis Pharmaceuticals Corporation, East Hanover, NJ.

\section{Availability of data and materials}

All data generated or analyzed during this study are included in this published article.

\section{Declarations}

Ethics approval and consent to participate

This study was conducted in accordance with the Guidelines for Good Pharmacoepidemiology Practices of the International Society for Pharmacoepidemiology, the Strengthening the Reporting of Observational Studies in Epidemiology guidelines, and the ethical principles in the Declaration of Helsinki. All database records were fully compliant with US patient confidentiality requirements, including the Health Insurance Portability and Accountability Act of 1996. As this study is a retrospective analysis of deidentified claims data in compliance with US patient confidentiality requirements and did not involve the collection, use, or transmittal of individually identifiable data, institutional review board approval was not required to conduct this study. Informed consent to participate was not applicable.

\section{Consent for publication}

Not applicable

\section{Competing interests}

A. Ogdie has received consulting fees from Amgen, AbbVie, Bristol Myers Squibb, Celgene, Corrona, Gilead, Janssen, Lilly, Novartis, Pfizer, and UCB and has received grant support from the National Institutes of Health/National Institute of Arthritis and Musculoskeletal and Skin Diseases, Rheumatology Research Foundation, National Psoriasis Foundation, Pfizer (University of Pennsylvania), Amgen (FORWARD Data Bank), and Novartis (FORWARD Data Bank). M. Rozycki and T. Arndt were employees of HVH Precision Analytics at the time of this analysis. C. Shi is an employee of Novartis Pharmaceuticals Corporation. N. Kim was a postdoctoral fellow at the University of Texas at Austin and Baylor Scott and White Health, providing services to Novartis Pharmaceuticals Corporation, at the time of this analysis. P. Hur was an employee of Novartis Pharmaceuticals Corporation at the time of this analysis.

\section{Author details}

${ }^{1}$ Perelman School of Medicine at the University of Pennsylvania, Philadelphia, PA, USA. ${ }^{2} \mathrm{HVH}$ Precision Analytics LLC, Wayne, PA, USA. ${ }^{3}$ Novartis Pharmaceuticals Corporation, East Hanover, NJ, USA. ${ }^{4}$ The University of Texas at Austin, Austin, TX, USA. ${ }^{5}$ Baylor Scott and White Health, Temple, TX, USA.

Received: 6 May 2021 Accepted: 12 September 2021

Published online: 01 October 2021

References

1. Gladman DD. Clinical features and diagnostic considerations in psoriatic arthritis. Rheum Dis Clin North Am. 2015;41(4):569-79. https://doi.org/10.101 6/j.rdc.2015.07.003.

2. Ritchlin CT, Colbert RA, Gladman DD. Psoriatic arthritis. N Engl J Med. 2017; 376(10):957-70. https://doi.org/10.1056/NEJMra1505557.

3. Coates LC, Kavanaugh A, Mease PJ, Soriano ER, Laura Acosta-Felquer M, Armstrong AW, et al. Group for Research and Assessment of Psoriasis and Psoriatic Arthritis 2015 treatment recommendations for psoriatic arthritis. Arthritis Rheum. 2016;68(5):1060-71. https://doi.org/10.1002/art.39573.

4. Ogdie A, Schwartzman S, Husni ME. Recognizing and managing comorbidities in psoriatic arthritis. Curr Opin Rheumatol. 2015;27(2):118-26. https://doi.org/10.1097/BOR.0000000000000152.

5. Wei JC, Baeten D, Sieper J, Deodhar A, Bhosekar V, Martin R, et al. Efficacy and safety of secukinumab in Asian patients with active ankylosing spondylitis: 52-week pooled results from two phase 3 studies. Int J Rheum Dis. 2017;20(5):589-96. https://doi.org/10.1111/1756-185X.13094.

6. McHugh NJ. Early psoriatic arthritis. Rheum Dis Clin North Am. 2015:41(4): 615-22. https://doi.org/10.1016/j.rdc.2015.07.005. 
7. Raychaudhuri SP, Wilken R, Sukhov AC, Raychaudhuri SK, Maverakis E. Management of psoriatic arthritis: early diagnosis, monitoring of disease severity and cutting edge therapies. J Autoimmun. 2017;76:21-37. https:// doi.org/10.1016/j.jaut.2016.10.009.

8. Ogdie A, Nowell WB, Applegate E, Gavigan K, Venkatachalam S, de la Cruz $M$, et al. Patient perspectives on the pathway to psoriatic arthritis diagnosis: results from a web-based survey of patients in the United States. BMC Rheumatol. 2020;4(1):2. https://doi.org/10.1186/s41927-019-0102-7.

9. Haroon M, Gallagher P, FitzGerald O. Diagnostic delay of more than 6 months contributes to poor radiographic and functional outcome in psoriatic arthritis. Ann Rheum Dis. 2015;74(6):1045-50. https://doi.org/10.113 6/annrheumdis-2013-204858.

10. Gottlieb AB, Mease PJ, Mark Jackson J, Eisen D, Amy Xia H, Asare C, et al. Clinical characteristics of psoriatic arthritis and psoriasis in dermatologists' offices. J Dermatolog Treat. 2006;17(5):279-87. https://doi.org/10.1080/0954 6630600823369

11. Truven Health Analytics. IBM MarketScan research databases for life sciences researchers. 2020. https://www.ibm.com/products/marketscan-research-data bases/databases

12. Sumner W, Stwalley DL, Asaro PV, Hagen MD, Olsen MA. Adding flexible temporal constraints to identify chronic comorbid conditions in ambulatory claims data. AMIA Annu Symp Proc. 2014;2014:1088-97.

13. Nickel KB, Wallace $A E$, Warren DK, Ball KE, Mines $D$, Fraser VJ, et al. Modification of claims-based measures improves identification of comorbidities in non-elderly women undergoing mastectomy for breast cancer: a retrospective cohort study. BMC Health Serv Res. 2016;16(a):388. https://doi.org/10.1186/s12913-016-1636-7.

14. Baldwin LM, Klabunde CN, Green P, Barlow W, Wright G. In search of the perfect comorbidity measure for use with administrative claims data: does it exist? Med Care. 2006:44(8):745-53. https://doi.org/10.1097/01.mlr.00002234 75.70440.07

15. Gladman DD, Thavaneswaran A, Chandran V, Cook RJ. Do patients with psoriatic arthritis who present early fare better than those presenting later in the disease? Ann Rheum Dis. 2011;70(12):2152-4. https://doi.org/10.113 6/ard.2011.150938.

16. Theander E, Husmark T, Alenius GM, Larsson PT, Teleman A, Geijer M, et al. Early psoriatic arthritis: short symptom duration, male gender and preserved physical functioning at presentation predict favourable outcome at 5-year follow-up. Results from the Swedish Early Psoriatic Arthritis Register (SwePsA). Ann Rheum Dis. 2014;73(2):407-13. https://doi.org/10.1136/a nnrheumdis-2012-201972.

17. Eder L, Tu K, Rosen CF, Alhusayen R, Cheng SY, Young J, et al. Health care utilization for musculoskeletal issues during the pre-diagnosis period in psoriatic arthritis - a population-based study. Arthritis Care Res (Hoboken). 2021;73(5):680-6. https://doi.org/10.1002/acr.24146.

18. Kavanaugh A, Helliwell P, Ritchlin CT. Psoriatic arthritis and burden of disease: patient perspectives from the population-based Multinational Assessment of Psoriasis and Psoriatic Arthritis (MAPP) survey. Rheumatol Ther. 2016:3(1):91-102. https://doi.org/10.1007/s40744-016-0029-z.

19. Desthieux C, Granger B, Balanescu AR, Balint P, Braun J, Canete JD, et al. Determinants of patient-physician discordance in global assessment in psoriatic arthritis: a multicenter European study. Arthritis Care Res (Hoboken). 2017;69(10):1606-11. https://doi.org/10.1002/acr.23172.

20. Betteridge N, Boehncke WH, Bundy C, Gossec L, Gratacós J, Augustin M. Promoting patient-centred care in psoriatic arthritis: a multidisciplinary European perspective on improving the patient experience. J Eur Acad Dermatol Venereol. 2016;30(4):576-85. https://doi.org/10.1111/jdv.13306.

21. Husted JA, Thavaneswaran A, Chandran V, Gladman DD. Incremental effects of comorbidity on quality of life in patients with psoriatic arthritis. J Rheumatol. 2013:40(8):1349-56. https://doi.org/10.3899//rheum.121500

22. Bergman M, Lundholm A. Mitigation of disease- and treatment-related risks in patients with psoriatic arthritis. Arthritis Res Ther. 2017;19(1):63. https:// doi.org/10.1186/s13075-017-1265-5.

23. Lebwohl MG, Kavanaugh A, Armstrong AW, Van Voorhees AS. US perspectives in the management of psoriasis and psoriatic arthritis: patient and physician results from the population-based Multinational Assessment of Psoriasis and Psoriatic Arthritis (MAPP) survey. Am J Clin Dermatol. 2016; 17(1):87-97. https://doi.org/10.1007/s40257-015-0169-x.

24. Scher JU, Ogdie A, Merola JF, Ritchlin C. Preventing psoriatic arthritis: focusing on patients with psoriasis at increased risk of transition. Nat Rev Rheumatol. 2019;15(3):153-66. https://doi.org/10.1038/s41584-019-0175-0.
25. Bhutani T, Wong JW, Bebo BF, Armstrong AW. Access to health care in patients with psoriasis and psoriatic arthritis: data from National Psoriasis Foundation survey panels. JAMA Dermatol. 2013;149(6):717-21. https://doi. org/10.1001/jamadermatol.2013.133.

26. Ogdie A, Weiss P. The epidemiology of psoriatic arthritis. Rheum Dis Clin North Am. 2015:41(4):545-68. https://doi.org/10.1016/.rdc.2015.07.001.

27. Villani AP, Rouzaud M, Sevrain M, Barnetche T, Paul C, Richard MA, et al. Prevalence of undiagnosed psoriatic arthritis among psoriasis patients: systematic review and meta-analysis. J Am Acad Dermatol. 2015;73(2):242-8. https://doi.org/10.1016/j.jaad.2015.05.001.

28. Mathew AJ, Bird P, Gupta A, George R, Danda D. Magnetic resonance imaging (MRI) of feet demonstrates subclinical inflammatory joint disease in cutaneous psoriasis patients without clinical arthritis. Clin Rheumatol. 2018; 37(2):383-8. https://doi.org/10.1007/s10067-017-3895-z.

29. Eder L, Jayakar J, Thavaneswaran A, Haddad A, Chandran V, Salonen D, et al. Is the MAdrid Sonographic Enthesitis Index useful for differentiating psoriatic arthritis from psoriasis alone and healthy controls? J Rheumatol. 2014;41(3):466-72. https://doi.org/10.3899/jrheum.130949.

30. Eder L, Polachek A, Rosen CF, Chandran V, Cook R, Gladman DD. The development of psoriatic arthritis in patients with psoriasis is preceded by a period of nonspecific musculoskeletal symptoms: a prospective cohort study. Arthritis Rheumatol. 2017;69(3):622-9. https://doi.org/10.1 002/art.39973.

31. Radtke MA, Reich K, Blome C, Rustenbach S, Augustin M. Prevalence and clinical features of psoriatic arthritis and joint complaints in 2009 patients with psoriasis: results of a German national survey. J Eur Acad Dermatol Venereol. 2009;23(6):683-91. https://doi.org/10.1111/j.1468-3083.2009.03159.x.

32. Haroon M, Kirby B, FitzGerald O. High prevalence of psoriatic arthritis in patients with severe psoriasis with suboptimal performance of screening questionnaires. Ann Rheum Dis. 2013;72(5):736-40. https://doi.org/10.1136/a nnrheumdis-2012-201706.

33. Mease PJ, Gladman DD, Papp KA, Khraishi MM, Thaci D, Behrens F, et al. Prevalence of rheumatologist-diagnosed psoriatic arthritis in patients with psoriasis in European/North American dermatology clinics. J Am Acad Dermatol. 2013;69(5):729-35. https://doi.org/10.1016/j.jaad.2013.07.023.

34. Reich K, Krüger K, Mössner R, Augustin M. Epidemiology and clinical pattern of psoriatic arthritis in Germany: a prospective interdisciplinary epidemiological study of 1511 patients with plaque-type psoriasis. $\mathrm{Br} \mathrm{J}$ Dermatol. 2009;160(5):1040-7. https://doi.org/10.1111/j.1365-2133.2008. 09023.x.

35. Mease PJ, Palmer JB, Hur P, Strober BE, Lebwohl M, Karki C, et al. Utilization of the validated Psoriasis Epidemiology Screening Tool to identify signs and symptoms of psoriatic arthritis among those with psoriasis: a cross-sectional analysis from the US-based Corrona Psoriasis Registry. J Eur Acad Dermatol Venereol. 2019;33(5):886-92. https://doi.org/10.1111/jdv.15443.

36. Bagel J, Schwartzman S. Enthesitis and dactylitis in psoriatic disease: a guide for dermatologists. Am J Clin Dermatol. 2018;19(6):839-52. https://doi.org/1 0.1007/s40257-018-0377-2.

37. Tillett W, Jadon D, Shaddick G, Cavill C, Korendowych E, de Vries CS, et al. Smoking and delay to diagnosis are associated with poorer functional outcome in psoriatic arthritis. Ann Rheum Dis. 2013;72(8):1358-61. https:/ doi.org/10.1136/annrheumdis-2012-202608.

38. Haberman R, Perez-Chada LM, Merola JF, Scher J, Ogdie A, Reddy SM. Bridging the gaps in the care of psoriasis and psoriatic arthritis: the role of combined clinics. Curr Rheumatol Rep. 2018;20(12):76. https://doi.org/10.1 007/s11926-018-0785-6.

39. Helliwell P, Coates L, Chandran V, Gladman D, de Wit M, FitzGerald O, et al. Qualifying unmet needs and improving standards of care in psoriatic arthritis. Arthritis Care Res (Hoboken). 2014;66(12):1759-66. https://doi.org/1 $0.1002 /$ acr.22404

40. Cobo-Ibáñez T, Villaverde V, Seoane-Mato D, Muñoz-Fernández S, Guerra M, Del Campo PD, et al. Multidisciplinary dermatology-rheumatology management for patients with moderate-to-severe psoriasis and psoriatic arthritis: a systematic review. Rheumatol Int. 2016;36(2):221-9. https://doi. org/10.1007/s00296-015-3377-z.

41. di Minno MN, Peluso R, lervolino S, Lupoli R, Russolillo A, Scarpa R, et al. Obesity and the prediction of minimal disease activity: a prospective study in psoriatic arthritis. Arthritis Care Res (Hoboken). 2013;65(1):141-7. https:// doi.org/10.1002/acr.21711.

42. Ibrahim GH, Buch MH, Lawson C, Waxman R, Helliwell PS. Evaluation of an existing screening tool for psoriatic arthritis in people with psoriasis and the 
development of a new instrument: the Psoriasis Epidemiology Screening Tool (PEST) questionnaire. Clin Exp Rheumatol. 2009;27(3):469-74.

43. Gladman DD, Schentag CT, Tom BD, Chandran V, Brockbank J, Rosen C, et al. Development and initial validation of a screening questionnaire for psoriatic arthritis: the Toronto Psoriatic Arthritis Screen (ToPAS). Ann Rheum Dis. 2009;68(4):497-501. https://doi.org/10.1136/ard.2008.089441.

44. Tom BD, Chandran V, Farewell VT, Rosen CF, Gladman DD. Validation of the Toronto Psoriatic Arthritis Screen Version 2 (ToPAS 2). J Rheumatol. 2015; 42(5):841-6. https://doi.org/10.3899/jrheum.140857.

45. Villeneuve E, Nam JL, Bell MJ, Deighton CM, Felson DT, Hazes JM, et al. A systematic literature review of strategies promoting early referral and reducing delays in the diagnosis and management of inflammatory arthritis. Postgrad Med J. 2013;89(1050):231-40. https://doi.org/10.1136/postgra dmedj-2011-201063rep.

46. Merola JF, Herrera V, Palmer JB. Direct healthcare costs and comorbidity burden among patients with psoriatic arthritis in the USA. Clin Rheumatol. 2018;37(10):2751-61. https://doi.org/10.1007/s10067-018-4187-y.

\section{Publisher's Note}

Springer Nature remains neutral with regard to jurisdictional claims in published maps and institutional affiliations.

Ready to submit your research? Choose BMC and benefit from:

- fast, convenient online submission

- thorough peer review by experienced researchers in your field

- rapid publication on acceptance

- support for research data, including large and complex data types

- gold Open Access which fosters wider collaboration and increased citations

- maximum visibility for your research: over $100 \mathrm{M}$ website views per year

At $\mathrm{BMC}$, research is always in progress.

Learn more biomedcentral.com/submissions 